\title{
A Postgraduate Programme on Information and Communication Systems Security
}

\author{
SOKRATIS K. KATSIKAS
}

Dept. of Information and Communication Systems, University of the Aegean, Karlovassi GR83200, Greece.E-mail: ska@aegean.gr

Key words: Security education, academic curricula, ERASMUS \& SOCRATES Programme

Abstract: $\quad$ A postgraduate (MSc-type) programme in Information and Communication Systems Security is described in detail in this paper. The programme description (syllabus) herein is full in the academic sense, i.e. it includes the programme overall structure, as well as credits per course, academic prerequisites, degree prerequisites, course timings, etc.

\section{INTRODUCTION}

Information and Communication Systems Security is a scientific area witnessing an explosion of interest in the past few years. This is due to the global proliferation of the communications infrastructure and the consequent rapid deployment of the Information Society. Even though the security needs have been increased as a result of this deployment, security professionals are scarce among IT professionals. Because IS security only recently was acknowledged as a scientific field, most of them have not had formal security education; their knowledge comes mostly from professional training and practical experience. However this form of acquiring qualifications may have (and has) been adequate up till now, it is generally accepted that the new era will require the services of educated (as opposed to trained) security professionals.

The original version of this chapter was revised: The copyright line was incorrect. This has been corrected. The Erratum to this chapter is available at DOI: 10.1007/978-0-387-35515-3_53 
This explains why there have been several efforts lately towards designing education programmes in the general area of information security. Such efforts include the International Federation for Information Processing (IFIP), Technical Committee 11, Working Group 11.8 (Computer Security Education), which is engaged in working on international University-level Programmes and courses in the area of information security. Also, within the Information Systems Audit and Control Association, (ISACA - formerly EDPAA), a survey on similar academic educational efforts world-wide has been conducted.

Recently, organisations such as the American Society for Industrial Security (ASIS), have started paying attention to information and computer security; this time from a traditional security management perspective. The organisation specifies demands on knowledge in the area within their professional certification scheme, as does ISACA. The British Computer Society (BCS), together with the Confederation of British Industry and the National Computer Users Forum, have prepared Guidelines on IT Security Training which "are offered to course providers and students of IT Security to provide them with expert information on what courses on IT Security should contain". The National Security Agency (NSA) designated, in 1999, the first centers of academic excellence in information assurance education.

This paper describes the work of the Inter-University Co-operation Programme on Information and Communication Systems Security, a group of over twenty European Universities with interest in INFOSEC; as such, this paper is a collaborative effort. The first version of this work was also presented in The First World Conference on Information Security Education of IFIP WG 11.8 that was held in Stockholm, in 1999 [KATSIKAS 1999].

The paper is organised as follows: In section 2, a short description of the SOCRATES/ERASMUS Programme of the European Union is given; in section 3, the structure of the Inter-University Co-operation Programme (ICP) on Information and Communication Systems Security is briefly discussed; in section 4, a brief survey of other academic programmes in the area of information security is briefly presented; in section 5 , the proposal that the ICP has developed for a postgraduate programme on Information and Communication Systems Security is presented. Finally, section 6 closes the paper by commenting on the group's current directions of work. 


\section{THE INTER-UNIVERSITY CO-OPERATION PROGRAMME (ICP) ON "INFORMATION AND COMMUNICATION SYSTEMS SECURITY"}

In 1994, under the framework of the then ERASMUS Programme [COMMISSION 2000], the Inter-University Co-operation Programme (ICP) on Information and Communication Systems Security was formed. Its objectives were

- To stimulate student and staff exchanges between the member

Universities

- To develop a proposal for a postgraduate curriculum on Information and

Communication Systems Security

- To implement this proposal in member Universities

- To develop a short intensive programme on Information and

Communication Systems Security.

and relevant activities were proposed for funding to the Commission.

The first three activities were approved for funding in the same year by DG XXII; approval of the fourth came under the SOCRATES Programme framework, in 1997.

The "founding" members of the ICP were 17 European Universities. Later, other Universities joined in, so that the current composition of the "consortium" comprises 22 partner Universities, in 10 European countries, as follows:

University of the Aegean (GR) (co-ordinator), Aristotles University of Thessaloniki (GR), Aston University (UK), Athens Univ. of Economics \& Business (GR), Chalmers University of Technology (S), Copenhagen Business School (DK), Katholieke Universiteit Leuven (B), Kingston University (UK), Lund University (S), Stockholm University (S), University of Athens (GR), University College Dublin (IRL), University of Essen (D), University of Hamburg (D), University of London - RHC (UK), University of Oulu (FIN), University of Patras (GR), University of Pireaus (GR), University of Plymouth (UK), University of Rome, La Sapienza (I), University of Technology Graz (A), University of Vienna (A).

\section{ACADEMIC CURRICULA ON INFORMATION AND COMMUNICATION SYSTEMS SECURITY}

As the first task towards fulfilling the objective of developing and implementing a postgraduate curriculum in Information and Communication Systems Security, a review of existing such curricula was carried out. 
The results of the study were published in a report entitled "Academic Curricula on Information and Communication Systems Security" [GRITZALIS, 1995]. The focus of this report was on Programmes offered by Universities located in the European Union Member States. However, one more Programme which was (and still is) being offered by a University located in Australia has been also identified and described briefly, for the shake of completeness.

A widely acknowledged problem with defining the area of information and communication systems security is how (or even whether) information security relates to information technology. Traditionally, Departments of Computer Science and Mathematics have dealt with technical security issues, Departments of Business Administration with organisational and managerial issues, Departments of Law with legal issues, Departments of Public Order with criminal issues and Departments of Audit with IT auditing issues. The idea that security is, in fact, a multidisciplinary issue is now widely accepted.

In 1995, only one out of four academic Computer Science departments offered any course whatsoever related to information security. It is common knowledge that this situation has been dramatically changed today, when practically no computer science graduate can obtain her/his degree without having attended at least one information security related course. Nevertheless, the situation with regards to the offering of complete academic programmes in the area is not very different than what it was in 1995. A search, performed over the WWW in January 2000, revealed that only a few universities around the world have made information security programs available to their students.

The Programmes that were studied in 1995 were being organised by the following Universities:

London School of Economics (United Kingdom), University of Hamburg (Germany), University of Leicester (United Kingdom) (two Programmes), University of London (Royal Holloway College) (United Kingdom) (two Programmes), University of York (United Kingdom), Stockholm University \& Royal Institute of Technology (Sweden) (three Programmes), Queensland University of Technology (Australia).

Current information on these programmes can be found at

- http://www.lse.ac.uk/graduate/programmes/179.htm

- http://www.informatik.uni-hamburg.de

- http://www.leicester.ac.uk/scarman

- http://www.isg.rhbnc.ac.uk/Course_Details.htm

- http://www.cs.york.ac.uk/gsp/index.html

- http://www.olt.qut.edu.au/IT/IT50/p_cStruF.htm respectively. 
In addition to these, the following universities are currently known to offer programmes on information security:

James Madison University (USA), George Mason University (USA), University of Idaho (USA), Algonquin College (Canada), Naval Postgraduate School (USA), Moscow State Engineering Physics Institute (Russia).

Current information on these programmes can be found at

- http://www.infosec.jmu.edu

- http://www.isse.gmu.edu

- http://www.cs.uidaho.edu/programs/info-secure/IA.htm

- http://www.algonquinc.on.ca/acad_menus/current/0445X1FWO.html

- http://cisr.nps.navy.mil/Classes.html

The main similarities among these Programmes lie in their structure, extent, duration, level and more-than-one subject orientation. Also, most Programmes consist of approx. $25 \%$ thesis-work and $75 \%$ course-work.

Differences are found in prerequisites, orientation and depth.

Taken together, the Programmes cover a wide range of subjects from mathematical, technical, computer science, administrative/management, law, and public order. Therefore, a student with a very specific interest in IT security should, through mixing courses from these Programmes, be able to design a personal profile.

The general profile of the Programmes is collectively shown in Figure 1.

\begin{tabular}{|l|l|l|l|l|}
\hline & \multicolumn{4}{|c|}{ Orientation/target groups } \\
\hline University & $\begin{array}{c}\text { Mathematical } \\
/ \text { Technical }\end{array}$ & $\begin{array}{c}\text { Computer } \\
\text { Science }\end{array}$ & $\begin{array}{c}\text { Administrative / } \\
\text { Managerial }\end{array}$ & Law \\
\hline LSE & & $\checkmark$ & $\checkmark$ & $\checkmark$ \\
\hline U. of Hamburg & $\checkmark$ & $\checkmark$ & $\checkmark$ & $\checkmark$ \\
\hline U. of Leicester & & & $\checkmark$ & $\checkmark$ \\
\hline U. of London & $\checkmark$ & $\checkmark$ & & \\
\hline Y. of York & $\checkmark$ & $\checkmark$ & & \\
\hline DSV/KTH & $\checkmark$ & $\checkmark$ & & \\
\hline DSV/SU & $\checkmark$ & $\checkmark$ & $\checkmark$ & $\checkmark$ \\
\hline QUT & $\checkmark$ & $\checkmark$ & & \\
\hline JMU & $\checkmark$ & $\checkmark$ & & $\checkmark$ \\
\hline GMU & $\checkmark$ & $\checkmark$ & & \\
\hline U. of Idaho & $\checkmark$ & $\checkmark$ & & \\
\hline Algonquin College & $\checkmark$ & $\checkmark$ & $\checkmark$ & $\checkmark$ \\
\hline NPS & $\checkmark$ & $\checkmark$ & $\checkmark$ & \\
\hline Moscow State EPI & $\checkmark$ & $\checkmark$ & & \\
\hline
\end{tabular}

Figure 1: Main orientation of the Programmes 


\section{AN M.S. CURRICULUM ON INFORMATION AND COMMUNICATION SYSTEMS SECURITY}

\subsection{Title}

The proposed postgraduate programme awards a degree in one of the following areas:

- MSc in Information Systems Security

- MSc in Computer and Communication Security

The specific degree to be awarded depends on the stream of courses the student has followed. The use of the "Master's of Science" (MSc) degree notion is suggested, since it has been well established in a number of European Union Member States, in North America and in Australia. Furthermore, it is expected that this structure could fit - one way or another in the educational system of a number of additional countries.

\subsection{Academic prerequisites}

In order for an individual to be eligible to register for the postgraduate Programme, he/she must have a BSc (or equivalent) degree in one of the following areas:

- Computer Science or Computer Engineering or Informatics or Information Systems

- Mathematics (with a sufficiently strong Computer Science background)

- Electrical or Electronic or Communications Engineering (with a sufficiently strong Computer Science background).

- Economics or Business Administration (with a sufficiently strong Computer Science background).

Finally, fulfilment of a number of additional requirements may be required by some institutions.

\subsection{Duration}

The Programme is expected to last for one and a half year, or equivalently - for 4 time periods.

Three of the time periods will be allocated to lectures and/or to laboratory work, while the fourth will be devoted to a research/industry project (thesis). The first two periods consist of 13 weeks, the third of 8 weeks and the fourth of 6 months. 


\subsection{Credits}

When the course was originally designed, the basic means of the academic accreditation used was the "credit". Specifically, a course is granted 1 credit if it is taught for 14 hours. Translation of this crediting system to the ECTS (European Credit Transfer System) system is currently underway.

In more detail, the first of the 14 hours is devoted to preparatory arrangements (e.g. introductions, detailed planning and scheduling of the course, evaluation procedures, etc.), and the remaining 13 hours are divided into thirteen 1-hour lectures (delivered for thirteen weeks). Thus, if a course is taught (lectures + laboratory work) for 3 hours/week, then the course will be granted 3 credits.

In the case of the third period, which lasts for only 8 weeks, a course will be granted 3 credits if it is taught (lectures + laboratory work) for 5 hours/week. As previously, the first hour will be devoted to preparatory work.

The research work is to be carried out for a period of 6 months (27 weeks, approximately). Each student will be supervised by at least one member of the academic staff. Regular meetings must be organised between the supervisor and the students. In the beginning of the fourth period, at least 3 hours must be devoted to preparatory work.

Therefore, credits are granted as shown in Figure 2.

In order for an individual to be awarded an MSc degree, s/he must complete successfully at least 24 credits plus an MSc thesis. The thesis will be carried out during the fourth period.

\begin{tabular}{|c|c|c|c|c|c|}
\hline Period & $\begin{array}{c}\text { Course } \\
\text { duration } \\
\text { (weeks) }\end{array}$ & $\begin{array}{c}\text { Lecture + } \\
\text { Lab work } \\
\text { (weekly) }\end{array}$ & $\begin{array}{c}\text { Preparatory } \\
\text { work }\end{array}$ & Total hours & $\begin{array}{c}\text { Credits } \\
\text { granted }\end{array}$ \\
\hline 1 & 13 & 3 & 1 & 40 & 3 \\
\hline 2 & 13 & 3 & 1 & 40 & 3 \\
\hline 3 & 8 & 5 & 1 & 41 & 3 \\
\hline 4 & 27 & n/a & 3 & - & 6 \\
\hline Total & 61 & - & 6 & - & - \\
\hline
\end{tabular}

Figure 2: Credit granting

\subsection{Streams}

Originally, the programme was divided into three streams: These were - Information Systems Security 
- Distributed Systems Security

- Dependable Systems

The stream on dependable systems was included at that time to reflect the attitude that was then being formed within the European Union that the notions of safety and dependability should be seen as closely inter-related to that of security. This attitude never really took off, for a variety of reasons. To reflect this situation, in a 1999 major restructuring effort of the proposed curriculum, the stream on dependable systems was dropped. Thus, the programme is now divided into two - closely interrelated - streams. Each stream results in the award of a specific MSc degree, as mentioned above.

These streams are the following:

- Information Systems Security

- Computer and Communication Security

\subsection{Courses}

The courses offered are of two types:

Mandatory courses

These courses are mandatory, regardless of the stream a student may wish to follow.

Stream elective courses

These courses provide a pool of electives for every student who follows the specific stream.

In general, the requirements for the award of one of the proposed MSc degree are the successful completion of 6 mandatory courses, 3 streamelective courses and an MSc thesis.

The suggested structure of the Programme is as follows:

\section{Mandatory courses}

M1 Principles of Information Security and Dependability

M2 Introduction to Cryptography

M3 Information Systems Security

M4 Computer and Communications Security

M5 Formal Software Development

M6 Legal Aspects of Secure Computing

\section{Stream-elective courses}

Stream 1: Information Systems Security

E1.1 General Systems Theory

E1.2 Security-oriented Project Management

E1.3 Social \& Ethical Issues of Secure Computing

E1.4 Strategic Aspects of I\&CT 
E1.5 Database Systems Security

E1.6 Standardisation, Certification \& Evaluation

E1.7 Network Security

Stream 2: Computer and Communications Security

E2.1 Network Security

E2.2 Advanced Network Security

E2.3 Advanced Cryptography

E2.5 Technical Realisation of Crypto-algorithms

E2.6 Database Systems Security

E2.7 Security-oriented Project Management

E2.8 Standardisation, Certification \& Evaluation

As a result, a typical program for full-time studies follows:

\section{FIRST PERIOD}

M1 Principles of Information Security, Dependability \& Safety

M2 Introduction to Cryptography

M3 Information Systems Security Management

\section{SECOND PERIOD}

M4 Computer Systems Security

M5 Formal Software Development

M6 Legal Aspects of Secure Computing

\section{THIRD PERIOD}

Stream 1: Information Systems Security

at least 1 out of

E1.1 General Systems Theory

E1.2 Social \& Ethical Issues of Secure Computing

E1.3 Strategic Aspects of I\&CT

and

at most 2 out of

E1.4 Security-oriented Project Management

E1.5 Database Systems Security

E1.6 Standardisation, Certification \& Evaluation

E1.7 Network Security

or

Stream 2: Computer and Communications Security

at least 1 out of

E2.1 Network Security

E2.2 Advanced Cryptography

E2.3 Technical Realisation of Crypto-algorithms and 
at most 2 out of

E2.4 Security-oriented Project Management

E2.5 Database Systems Security

E2.6 Standardisation, Certification \& Evaluation

E2.7 Advanced Network Security

\section{FOURTH PERIOD}

TH MSc Thesis (research work or industry placement)

\section{CONCLUSIONS - WHAT LIES AHEAD}

The Inter-University Co-operation Programme continues its work towards collecting and developing teaching material for the programme, setting up this material on its Web site and making as much of it as possible available to other interested parties, carrying out the Intensive Programme on Information and Communication Systems Security (IPICS) and exchanging staff and students. It is hoped and expected that this kind of work will prove useful to academic institutions world-wide. The current group of cooperating Universities is not closed; on the contrary, it is the wish of all participating institutions be enlarged as much as possible to embrace all European countries so that it may be used effectively for bridging cultural differences related to information security.

\section{REFERENCES}

[COMMISSION, 2000] http://europa.eu.int/comm/education/socrates.html

[GRITZALIS, 1995] Gritzalis D. (Ed.), University Programmes on Information Security, Dependability and Safety, European Commission, Erasmus ICP, Project ICP-94(\&95)-G4016/11, Report IS-CD-3c, Athens, 1995.

[KATSIKAS \& GRITZALIS, 1995] Katsikas, S. and Gritzalis D. (Eds.), A proposal for a postgraduate programme on Information Security, Dependability and Safety, European Commission, Erasmus ICP, Project ICP-94(\&95)-G-4016/11, Report IS-CD-4a, Athens, 1995.

[KATSIKAS, 1999] Katsikas, S., Academic Curricula and Curricula Developments in Europe - The ERASMUS/SOCRATES Approach, in Proceedings of the IFIP TC11 WG11.8 First World Conference on Information Security Education (WISE1), Stockholm University, 1999. 